\title{
Article \\ Understanding Football as a Vehicle for Enhancing Social Inclusion: Using an Intervention Mapping Framework
}

\author{
Daniel Parnell *, Andy Pringle, Paul Widdop and Stephen Zwolinsky \\ Centre for Active Lifestyles, Institute of Sport, Physical Activity and Leisure, Leeds Beckett University, Leeds, LS6 3QS, \\ UK; E-Mails: d.parnell@leedsbeckett.ac.uk (D.P.), a.pringle@leedsbeckett.ac.uk (A.P.), p.widdop@leedsbeckett.ac.uk \\ (P.W.), s.zwolinsky@leedsbeckett.ac.uk (S.Z.) \\ * Corresponding author
}

Submitted: 10 September 2014 | In Revised Form: 25 January 2015 | Accepted: 28 January 2015 |

Published: 25 June 2015

\begin{abstract}
This article outlines a partnership between an academic institute and a third sector organisation attached to a professional football club in the United Kingdom. The partnership concerns a sport for development intervention. The purpose of the article is to outline the development of applied monitoring and evaluation and the application of intervention mapping for an intervention to tackle anti-social behaviour through a football-based social inclusion project for children and young people. This case supports the development of third sector-university partnerships and the use of intervention mapping to meet shared objectives in relation to articulating the impact of interventions to funders and for research outputs.
\end{abstract}

\section{Keywords}

community; evaluation; football; research partnership; social inclusion

\section{Issue}

This article is part of the special issue "Sport for Social Inclusion: Critical Analyses and Future Challenges", edited by Dr. Reinhard Haudenhuyse (Vrije Universiteit Brussel, Belgium) and Professor Marc Theeboom (Vrije Universiteit Brussel, Belgium)

(C) 2015 by the authors; licensee Cogitatio (Lisbon, Portugal). This article is licensed under a Creative Commons Attribution 4.0 International License (CC BY).

\section{Background}

Since the 1970s and 1980s recreation and welfare policies have underpinned more recent (1990s) political acclaim attached to sport for its potential impact on social welfare and its regenerative qualities (Coalter, 2007). Sport was thought to be a mechanism that could increase income and jobs, improve education, health and social inclusion (Houlihan \& White, 2002; PAT 10, 1999). Furthermore, it has been noted that the impact of sport, particularly football, extends to domains that are considered harder to reach through more traditional political and civic activities (Mellor, 2008; Parnell \& Richardson, 2014). Indeed, sport has been recognised as a potential vehicle to enhance health, engage "at-risk" children and young people (aged between 6-25 years) build stronger and safer communities and combat anti-social behaviour (ASB) (Bloyce \& Smith, 2010; Coalter, 2007; Collins \& Kay, 2014; Parnell \& Richardson, 2014). Nevertheless, authors have challenged the notion that sport can facilitate social benefits, highlighting that this claim often lacks empirical evidence (Bailey, 2005; Coalter, 2007; Collins \& Kay, 2014; Smith \& Waddington, 2004).

Smith and Waddington (2004, p. 281) argued that support for sport-based social inclusion projects among policy makers and practitioners is "based on an uncritical perception of sport as an unambiguously wholesome and healthy activity in both a physical and moral sense". Further, Walker, Heere and Kim (2013, p. 313) 
stressed that some sports based interventions experience "evaluation-phobia", whereby project leaders fear the collection of hard evidence as it may in essence demonstrate programme ineffectiveness. This may only offer a one-sided perspective of project leaders, neglecting those who are actively engaged in the pursuit of "evidence". The emerging problem is that this lack of measurement and evidence often leaves these community programmes uninformed and underevaluated (Levermore, 2011). Intrinsically, and often incorrectly-this is not seen as a catastrophe by a number of project leaders, sport researchers and policy makers (Coalter, 2007). However, given that policy makers continually rely on a sound evidence base (or at least evidence which is political comfortable) there remains a real need to evaluate and make a clearer assessment of the contribution sport is assumed to make in the promotion of greater social inclusion.

Sport's potential to contribute positively to a range of social issues is widely celebrated (Bloyce \& Smith, 2010; Coalter, 2007; Collins \& Kay, 2014; Parnell \& Richardson, 2014). The underpinning notion is that participation in sport can support social inclusion (i.e., reduce crime, develop communities and/or improve health) (Coalter, 2007). These presumed outcomes and subsequent policy rationales have rarely been articulated systematically or monitored and evaluated (Coalter, 2007). Indeed, empirical evidence for such benefits is limited and authors have challenged this shortfall calling for more rigorous and sustained programme outcomes and process evaluations (Bailey, 2005; Coalter, 2007; Collins \& Kay, 2014; Parnell \& Richardson, 2014; Pringle et al., 2014; Tacon, 2007). Broadly, Coalter (2008) highlights that sport rarely achieves the desired outcomes accredited to participation. He continues to call for a greater understanding of the issue of process and context to maximize its development potential (Coalter, 2008). As such, the quest for evidence-based policy-making in the UK often leaves policy makers ill-equipped and ill-informed (Pawson, 2006; Coalter, 2008). Despite this apparent lack of evidence to support the social role of sport and football, it has (in the past) been positioned by the UK government as a key vehicle to generate greater social inclusion for children and young people (Tacon, 2007; Parnell \& Richardson, 2014).

Of all British sports, it is perhaps football which has the greatest potential to reach and engage large numbers of children and young people. Owing to this apparent mass media youth appeal (Smith \& Westerbeek, 2007), it has received support as a vehicle to deliver on the social inclusion agenda. Within England, Football in the Community (FitC) programmes, which are often organised as independent registered charities attached to professional football clubs, lead the social welfare and corporate social responsibility agenda for football (Anagnostopoulos \& Shilbury, 2013; Parnell et al.,
2013; Walters, 2009; Walters \& Chadwick, 2009). Watson (2000) originally suggested that FitC schemes are identified as organisations that can aid the development of a range of social outcomes including sport participation rates, drug and alcohol abuse, social exclusion and health (which has been echoed more recently by Parnell and Richardson, 2014).

It is necessary to position this debate in the current political and economic context. Whilst unprecedented amounts of public and private money has in recent times (1997-2008) been targeted at sport based organisations (including professional football clubs FitC programmes), this has since been replaced by an age of public spending austerity. There is currently an increased likelihood of funding cuts and increased scrutiny on the impact of any investments (Pringle, McKenna, \& Zwolinksy, 2013; Parnell, Millward, \& Spracklen, 2014). Given this situation, it is likely that critical questions will be asked about what should and should not be funded. As such, the need to develop meaningful research and evaluation is a necessity. As a result of continued funding without an increase in scrutiny on the effectiveness of investment, could maintain the status quo for many policy-makers, practitioners and some researchers.

Using football to tackle the health agenda has begun to gather evidence (Bingham et al., 2014; Curran et al., 2014; Parnell et al., 2013; Pringle et al., 2013). Current understanding about football shows that this intervention option can offer some valuable health improvement programme success (Bangsbo et al., 2014). From engaging "hard-to-reach" groups (Pringle et al., 2014), delivering weight reduction (Hunt et al., 2014; Rutherford et al., 2014), delivering social inclusion (Parnell \& Richardson, 2014), supporting social capital (Bingham et al., 2014; Ottesen, Jeppesen, \& Krustrup, 2010) and other positive physiological changes across various groups (Bangsbo et al., 2014). The emerging social welfare remit attached to football, its reach and its associations with social inclusion and behaviour change, has resulted in its delivery to tackle issues such as ASB in children and young people (Kickz, 2009).

Within the UK context there has been increasing concern over the levels of criminal and ASB committed by young people (Boreham \& McManus, 2003; Condon $\&$ Smith, 2003). ASB is an often-difficult term to define, in that it encompasses what can be highly stigmatised activity such as young people being in large groups, making noise and behaving in a manner not accepted by some people. Furthermore, ASB is also an umbrella term, whereby several acts can be classed as forms of ASB. The ASB act (UK Government, 2003) defines it as the behaviour by a person, which causes or is likely to cause harassment, alarm or distress to one or more persons not of the same household as the person. As such, ASB is a difficult and complex term (Nixon et al., 2003). As the UK government has sought interventions to tack- 
le ASB, sport and football have been highlighted as a vehicle for enhancing social inclusion and reducing ASB.

One major football based intervention delivered nationally through FitC programmes to tackle ASB in children and young people was "Kickz" (2009). This programme was part of a system designed by the Laureus Sport For Good Foundation; in which three major sports were used as a vehicle to combat crime rates and ASB. Kickz was designed to build safer, stronger, more respectful communities through the development of young people's potential. It involved 42 professional football clubs, delivering 112 projects across the whole of England. "Kickz" showed a $60 \%$ reduction in ASB; along with a $28 \%$ reduction in criminal damage rates (Kickz, 2009). Football and FitC programmes were shown to be a key element in the success of the programme. Similar findings were suggested by Ramella (2004) in their evaluation of Positive Futures, a similar sport-based intervention (that used football). However, as with many other football-based interventions, there remains little clarity on whether such interventions actually work and the process in which any changes occur. Indeed, the Youth Justice Board highlighted the difficulty in attributing changes in ASB levels to specific interventions (Youth Justice Board for England and Wales, 2011). Essentially, there is no supporting empirical evidence that has been systematically collected showing the relationship between football (or sport) and a reduction in ASB.

The lack of empirical evidence on the relationship between sport and ASB may be a result of project evaluations tendency to focus on sporting outcomes. Moreover, the methodological difficulty of identifying sport's precise contribution and the challenge of establishing cause and effect in behavioural change may also contribute to a lack of evidence (Coalter, 2007). However, research in this area, particularly in football is beginning to emerge (Bingham et al., 2014; Curran et al., 2014; Parnell et al., 2013; Parnell \& Richardson, 2014; Pringle et al., 2014). Yet there remains a need to provide support for football-based practitioners, who often lack the required skill-set, develop effective and workable evaluation strategies for their interventions (Parnell, Pringle, et al., 2014; Walker, Heere, \& Kim, 2013).

At the same time, academic institutes, particularly those in higher education are facing their own respective challenges. In the UK, the government have undertaken a comprehensive spending review in 2010, which outlined $f 81$ billion of cuts across government departments by $2014 / 15$. Such cuts have had a range of subsequent economic constraints for society. The resource limitations have also had an impact on academic institutes. As such, the national economic climate has resulted in reduced funding for universities, who are experiencing reduced access to research council funding (Larkin, Richardson, \& Tabreman, 2012). As such, in order to ensure universities develop applied research ac- tivities that endeavor towards "impact", new approaches are required to develop meaningful opportunities. On a similar level, the government public sector funding cuts, as part of the Conservative Liberal Democrat reform, which are premised on the "Big Society", has resulted a greater reliance on the third sector (Coote, 2010; Gleave et al., 2010; Parnell, Millward, et al., 2014). At the same time, third sector organisations, including those attached to professional football clubs are being required to sustain and develop intervention delivery and evaluation (Pringle et al., 2013).

The aim of this short communication is to demonstrate the development of a partnership and the application of intervention mapping. Whilst intervention mapping has been used previously for health-based interventions in sport, it has not (to the best of the authors knowledge) been deployed in social inclusion sport based interventions. This article may be beneficial for organisations planning to develop evaluations that aim to understand how interventions can tackle ASB through football-based social inclusion projects with children and young people.

\section{Burton Albion Community Trust: Albion 2 Engage (2014)}

Leeds Beckett University has an extensive portfolio of research partnerships in sport and leisure, including one with Burton Albion Community Trust (BACT). BACT is the community arm and registered charity of Burton Albion Football Club, a professional football club. The authors have developed a range of health improvement based research projects over several years with BACT (Parnell, Hargreaves, et al., 2014; Pringle et al., 2014).

BACT is located in the town of Burton, which is located in East Staffordshire in the English West Midlands, United Kingdom (UK) and has a population of 113,583 . Data on deprivation indicates there are 70 lower layer super output areas (LSOAs-a measure of deprivation) across East Staffordshire (East Staffordshire Borough Council, 2013). The East Staffordshire Local Strategic Community Safety Plan 2014-17 (2014) outlines three broad aims, (i) enhance the local environment, (ii) improve employability and (iii) live healthy. Within this document there is a number of objectives related to tackling a range of local social inclusion concerns. Amongst them is the objective to increase community cohesion and involvement, tackle ASB, continue to tackle crime as a priority and focus on the neighborhoods of concern. In response to this and as part of a broader strategy for the region, BACT have been commissioned support the plan's strategic objectives through their Albion 2 Engage intervention.

In 2011/12, official crime statistics indicated that that there were 1,235,028 arrests in England and Wales; of which 167,995 were of people in the age cohort of 10-17 (Home Office, 2014). Of the 167,995 ar- 
rests, 30,778 (18\%) were placed in custody. Overall, there were 273 ASB orders (ASBO) distributed in the year of 2012 and with 2,883 children and young people being given Penalty Notices for Disorder (PND). Within the past 15 years in the UK, there have been a total of 23,078 ASBO's issued to people aged 10 and above (Home Office, 2013). Research undertaken shows that $83 \%$ of Britons believe that ASB is a growing problem in the country; $79 \%$ of these blaming a lack of discipline as the main contributory factor, closely followed by $68 \%$ attributing the outcomes to at alcohol usage (ADT, 2006). Due to increased concerns associated with ASB, it has become much more prominent in debates within government resulting in past and current political parties implementing interventions in an attempt to tackle ASB, especially through football (Kickz, 2009; Ramella, 2004).

Albion 2 Engage is a football (and sport) based intervention that uses diversionary activities to focus children and young people into positive activities. These are delivered within notoriously "hard to reach" wards or priority neighbourhoods (i.e., those wards with high ASB levels or those that represent indices of multiple deprivation) across the Burton area of East Staffordshire to tackle ASB. Albion 2 Engage aims to target areas of the community through positive (i.e., fun and enjoyable) football and sport activities that attempts to reduce ASB and improve community cohesion. Albion 2 Engage uses the brand and appeal of the football club badge to attempt to inspire children and young people across local communities. This is provided alongside the engagement of key stakeholder organisations to deliver a targeted approach to supporting children and young people (BACT, 2014). The intervention is delivered in the following wards (i.e., geographical boundaries that contribute to a county in the UK): Shobnall, Stapenhill, Winshill, Horninglow, Eton Park and Anglesey. This is delivered through the utilisation of community outreach settings, such as multi-use games areas, local parks, playing areas or transportable playing areas. However, further sport provision is available such as cricket and basketball dependent on participant choice and accessibility of facilities. All activities are delivered by BACT coaching staff. BACT staff are typically English FA (Football Association) Level 2 Football Coaching qualified and often possess a range of other Level 1 and Level 2 national governing body sporting qualifications. Whilst football and sport based activities are the main constituent of the intervention, BACT offer reward mechanism for positive behaviour and engagement within the intervention. These additional activities include stadium tours, match day experiences, sport tournaments and celebration events.

The following section aims to provide both insight and context into the development of the research partnership between BACT and Leeds Beckett University. In describing this process, applied to monitoring and evaluation, we have used components of "intervention mapping" as an organising framework (i.e. evaluation needs, planning and implementation) (Ransdell, et al., 2009). Whilst intervention mapping has been used elsewhere in football based interventions (Pringle et al., in press), there remains a significant lack of structure and evaluation in sport and social inclusion projects (Bailey, 2005).

\section{Evaluation Needs}

In a era of reduced public spending on sport and leisure (APSE, 2012), amidst a climate of austerity measures set by the government (Parnell, Millward, et al., 2014) we now, more than ever see the need for partnership working as a key facet in community sport (Tett, 2005). In a bid to tackle strategic priorities across the East Staffordshire area and attend to the objectives of East Staffordshire Local Strategic Community Safety Plan 2014-17 (2014) a range of sport based community projects emerged, including Albion 2 Engage. Yet, there remained a real need and interest to develop evaluation strategies for BACT social inclusion based interventions. Given the literature previously discussed, it is apparent that policy makers, commissioners and the sport for development literature would benefit from greater insight into the development of partnerships and subsequent evaluation frameworks to capture the impact of football based social inclusion interventions (Bailey, 2005).

Football has evolved from its early days of delivering school based coaching programmes to attract new supporters (Parnell et al., 2013; Watson, 2000). Indeed, clubs and their respective community progammes are delivering on key agendas such as social inclusion (Parnell \& Richardson, 2014). BACT is no different to many football clubs, who focus their efforts on the delivery of football based community programmes that utilise the potential of the "brand" (Bingham et al., 2014) to recruit and engage participants (Pringle et al., 2014). To help BACT evidence the impact of Albion 2 Engage to a range of stakeholders an agreement was made as part of the commissioning process. The specific distribution of outcome measures and responsibilities are highlighted within the East Staffordshire Local Strategic Community Safety Plan 2014-17 (2014). The Plan is influenced by the pan Staffordshire strategy of the Police and Crime Commissioner, which has set out distinct themes of community safety. The contribution of Albion 2 Engage to the broader strategic Plan, including the need for the BACT evaluation concerned focusing on priority neighbourhoods and ensuring positive outcomes for families on the Building Resilient Families Programme (i.e., working with children and young people). Evaluating the impact of the Albion 2 Engage was necessary to establish intervention effect, and fundamental for sustaining resources for continued de- 
livery (Parnell \& Burrows, 2014). A compounding problem was the lack of expertise within BACT to develop and apply monitoring and evaluation, something that is echoed within the literature (Parnell et al., 2013).

A contributing factor to the development of this partnership were the demands of the higher education sector. Particularly, the demand to deliver "impact" through community engagement and research outputs, a challenge multiplied by reduced availability of funding (Larkin et al., 2012). As such, this current situation supports the development of partnerships with third sector organisation's that are currently responding to the impact of the economic downturn. This includes the added pressure to evidence a return on investment, whether that be social, health or economic, through intervention evaluation (Pringle et al., 2013). In electing to act on these needs, BACT contacted Leeds Beckett University in 2013/14 to provide consultation surrounding the evaluation of Albion 2 Engage (BACT, 2014).

\section{Evaluation Planning}

Over a number of years the BACT management team and authors (originally the first author) began discussions to expand internal BACT-led evaluation techniques to develop effective evaluation strategies to gauge the impact of Albion 2 Engage. An original preliminary evaluation was undertaken which involved surveys with children and young people, stakeholder partners (including Staffordshire Police, Trent and Dove Housing and East Staffordshire Borough Council), which was supplemented with an analysis of ASB and crime statistics provided by Staffordshire Police. Key evaluation findings are presented in the project report (Parnell \& Burrows, 2014). This initial preliminary evaluation preparation and engagement helped develop collaborative discussions surrounding the organisations strategy towards an intervention mapping framework, planning and evaluation discussed within this article.

The first meeting concerned the project outcomes, current monitoring and evaluation processes, any perceived or experienced barriers to evaluation (such as time and staff skill-set) and both internal and external resources related to the delivery of and future funding for the Albion 2 Engage intervention. Following this, a series of meetings were organised with the community coaches/practitioners that coordinate and deliver the intervention. This led the research team to develop a bespoke evaluation that aimed to measure the impact of Albion 2 Engage. The meetings have informed the following impact outcomes evaluations, which were included the data collection process.

The data collected included ASB; current and past activity, intention to engage in, peer influence and ASB statistics provided by (i) the Fire Service and (ii) the Police at different spatial scales (ward, district, region, and nationally). Further, a growing body of empirical evidence demonstrates that the contextual factors that impact upon a community or neighborhood has a bearing on a range of personal, psychosocial behaviours. Notably, poor economic conditions, opportunities, housing instability, crime rates and quality of life can impact school achievement, and influence emotional and behaviour problems in children and young people (Fauth, Leventhal, \& Brooks-Gunn, 2007; Kohen et al., 2008; Leventhal \& Brooks-Gunn, 2000; Prezza \& Pacilli, 2007). Further Nixon et al. (2003) highlighted ASB is dependent on context, location, community tolerance and quality of life expectations. In order to develop an understanding that attempts to capture such complexities, measurement markers included, different aspects of social capital and community cohesion (belonging, neighbourhood trust, generalised trust and social support). The survey explored whether engagement in the intervention was new or replacement activity (if the adopted activity was a substitute or new). The next section explored lifestyle information (including smoking and alcohol). Whilst smoking prevalence among young people in developed countries has been falling over the past 20 years, smoking prevalence rates among 15 year olds in Europe resides at approximately $28 \%$ (Hibell et al., 2011). Moreover, recent studies have shown sport may offer an opportunity to educate young people about elements of smoking and health (Romeo-Velilla et al., 2014). Nebury-Birch et al. (2009) also highlighted that ASB and interpersonal problems in young people can be a predictive factor of alcohol (and substance) misuse in future life. A measure of quality of life was taken given the breadth of associated factors that appear to contribute to ASB. Finally, demographic profiles (including age, gender, ethnicity and post-code) and affiliation to football and/or football clubs (i.e., football fan, non-fan, fan of host club) were collected which aligned with previous research in football and social change contexts (Bingham et al., 2014; Pringle et al., 2014). The evaluation outlined above is the self-report approach to data collection via an online survey (university commissioned version of Google documents) based on past research on football interventions (Pringle et al., 2014). These evaluations can be supplemented by further evaluation approaches as and when required, including qualitative research such as semi-structured interviews or focus groups as used in similar football-led interventions with children and young people (Parnell et al., 2013). Prior to any data collection the research team secured university research ethical clearance for the evaluation activities to take place.

Once the evaluation had been formalised the Leeds Beckett research team provided project specific capacity building with community coaches and practitioners. This professional development, that was typically delivered formally over one-day (supported by a number 
of informal support sessions prior to, throughout and post data collection), allows for "leads for the evaluation" BACT staff to develop. Developing the coach, as a researcher was especially important for the development of a rapport to work with and gain access to this target group (Parnell et al., 2013). This contributes to a developmental approach to project delivery to occur and any such changes to be tracked over the duration of the research and intervention. This allowed for effective elements of the intervention to be confirmed and also provided impact results. These results could then be shared with key stakeholders and commissioners and/or funders.

\section{Evaluation Implementation}

Once the research began, recruitment for the surveys were undertaken across the various Albion 2 Engage service delivery locations and delivered by the research team and BACT staff. Anonymity was maintained throughout. The research team attended and supported baseline data collection, ensuring and supporting the evaluation lead within BACT with the process of informed consent and delivery of the survey. This was completed in a supportive and collaborative manner. Where appropriate the research team offered guidance and support to ensure a consistent approach to data collection. Ongoing communication between the research team and BACT (both senior management and leads for evaluation) and research team was maintained through a range of techniques (informal and formal meetings, telephone calls and emails), aligned with the development of effective partnerships (Kihl, Babiak, \& Tainsky, 2014). In the future, the research team would provide analysis and reports on the data collected to support BACT stakeholder dissemination.

A fundamental aim of the partnership between Leeds Beckett University research team and BACT, was (and is) to develop a meaningful and mutually beneficial approach to research and evaluation. The national economic climate and subsequent austerity cuts (APSE, 2012; DCMS, 2010; Parnell, Millward, et al., 2014), accompanied by a drive for more efficient and effective practice within academic institutes and third sector organisations (including those attached to professional football clubs, FitC programmes) has developed a new priorities. This includes the need for organisations to develop new ways to effectively partner (Larkin et al., 2012). By doing so, such partnerships will allow for academic institutes in the higher education sector to build community engagement with third sector organisations.

Initial observations from implementation indicate the potential of this approach when assessing programme impact, which may provide positive research and evaluation outputs. This is particularly important, in an era of reduced funding for research (Larkin et al., 2012). Within this socio-political context, third sector organisations must react to reductions in funding, as government pursues the "Big Society" initiative (Coote, 2010; Gleave et al., 2010). The third sector has not been isolated from the impact of the economic downturn. Indeed, in the pursuit for more value for money, return on investment and the growing need to assess programme impact, third sector organisations including FitC programmes have felt an urgency and drive to provide evidence, in order to sustain and develop intervention delivery and evaluation (Pringle et al., 2013).

This partnership approach (South \& Tilford, 2000) and organisational framework for evaluation (intervention mapping), allows BACT the opportunity to utilise the impact evidenced from the evaluation activity. This includes allowing effective elements of the intervention to be confirmed. Furthermore, the evaluation enables subsequent impact results to be shared with key stakeholders and commissioners or funders, to strengthen the case for resources for sustained and/or enhanced provision. Going forward this is important in generating evidence for future practice and contributing to the academic literature.

\section{Conclusion}

The aims of this short article, was to demonstrate the development of a partnership and the application of intervention mapping. In doing so, this article provides a clarion call for academic institutes to work more closely with third sector organisations in football who, in this socio-economic and political context appear to require additional support. The article offers a potential way forward to support academic institute research objectives, third sector resource and evaluation needs, whilst offering a contribution to the advancement of wider knowledge and understanding football (sport) for development.

\section{Acknowledgements}

In preparing this manuscript the authors most gratefully acknowledge the staff of Burton Albion Football Club and Burton Albion Community Trust, notably Andy Taylor and Matt Hancock for their ongoing support. Furthermore, we would like to acknowledge and applaud the past and ongoing contribution of the social inclusion steering group led by Burton Albion Community Trust and supported by their extensive local partners. Finally, Leeds Beckett University (formerly Leeds Metropolitan University) and the Higher Education Innovation Fund who provided the resources for this work to be undertaken.

\section{Conflict of Interests}

The authors declare no conflict of interests. 


\section{References}

ADT. (2006). Anti-social behaviour across Europe. An overview of research commissioned by ADT Europe. Middlesex: ADT Fire and Security plc.

Anagnostopoulos, C., \& Shilbury, D. (2013). Implementing corporate social responsibility in English football: Towards multi-theoretical integration. Sport, Business and Management: An International Journal, 3(4), 268-284.

Association for Public Service Excellence (APSE). (2012). Local authority sport and recreation services in England: Where next? Manchester: APSE. Retrieved from http://www.apse.org.uk/apse/index.cfm/ research/current-research-programme/localauthority-sport-and-recreation-services-in-englandwhere-next/local-authority-sport-and-recreationservices-in-england-where-next

Albion 2 Engage. (2014). Burton Albion Community Trust. Retrieved from http://burtonalbioncommuni tytrust.co.uk

Bailey, R. (2005). Evaluating the relationship between physical education, sport and social inclusion. Educational Review, 57(1), 71-90.

Bangsbo, J., Junge, A., Dvorak, J., \& Krustrup, P. (2014). Executive summary: Football for health-Prevention and treatment of non-communicable diseases across the lifespan through football. Scandinavian Journal of Medicine \& Science in Sports, 24, 147150.

Bingham, D. D., Parnell, D., Curran, K., Jones, R., \& Richardson, D. (2014). Fit fans: perspectives of a practitioner and understanding participant health needs within a health promotion programme for older men delivered within an English Premier League football club. Soccer \& Society, 15(6), 883901.

Bloyce, D., \& Smith, A. (2010). Sport policy and development: An introduction. London: Routledge.

Boreham, R., \& McManus, S. (2003). Smoking, drinking and drug use among young people in England in 2002. London: Stationery Office.

Coalter, F. (2007). A wider social role for sport: Who's keeping the score? New York: Routledge.

Coalter, F. (2008) Sport-in-development: Development for and through sport? In M. Nicholson \& R. Hoye (Eds.), Sport and social capital (pp. 39-67). Oxford: Elsevier Butterworth-Heinemann.

Collins, M., \& Kay, T. (2014). Sport and social exclusion. London: Routledge.

Condon, J., \& Smith, N. (2003). Prevalence of drug use: Key findings from the 2002/2003 British Crime Questionnaire. London: Home Office.

Coote, A. (2010). Ten big questions about the big society and ten ways to make it the best of it. Retrieved from http://www.neweconomics.org/publications/ entry/ten-big-questions-about-the-big-society
Curran, K., Bingham, D. D., Richardson, D., \& Parnell, D. (2014). Ethnographic engagement from within a Football in the Community programme at an English Premier League football club. Soccer \& Society, 15(6), 934-950.

Department for Culture, Media and Sport (DCMS). (2010). News stories: Free swimming programme. Retrieved from http://www.culture.gov.uk/news/ news_stories/7193.aspx

East Staffordshire Borough Council. (2013). Retrieved from http://www.eaststaffsbc. gov.uk/Services/ SportEastStaffs/Pages/CommunitySportandPhysical ActivityNetwork.aspx

Fauth, R., Leventhal, T., \& Brooks-Gunn, J. (2007). Welcome to the neighborhood? Long-term impacts on moving to low-poverty neighborhoods on poor children's and adolescents' outcomes. Journal of Research on Adolescence, 17, 249-284.

Gleave, R., Wong, I., Porteus, J., \& Harding, E. (2010). What is "more integration" between health and social care? Results of a survey of Primary care trusts and Directors of Adult Social Care in England. Journal of Integrated Care, 18(5), 29-44.

Hibell, B., Guttormsson, U., Ahlström, S., Balakireva, O., Bjarnason, T., Kokkevi, A. \& Kraus, L. (2011). The 2011 ESPAD Report. Substance use among students in 36 European countries. Stockholm: The Swedish Council for Information on Alcohol and other Drugs.

Home Office. (2013). Anti-social behaviour order statistics: England and Wales 2012. London: Home Office.

Home Office. (2014). Youth justice statistics 2011/12. Retrieved from: https://www.gov.uk/government/ uploads/system/uploads/attachment_data/file/ 278549/youth-justice-stats-2013.pdf

Houlihan, B., \& White, A. (2002). The politics of sports development: Development of sport or sport for development. London: Routledge.

Hunt, K., Wyke, S., Gray, C. M., Anderson, A. S., Brady, A., Bunn, C., Donnan, P. T., Fenwick, E., Grieve, E., Leishman, J., Miller, E., Mutrie, N., Rauchhaus, P., White, A., \& Treweek, S. (2014). A gender-sensitised weight loss and healthy living programme for overweight and obese men delivered by Scottish Premier League football clubs (FFIT): A pragmatic randomised controlled trial. The Lancet, 383(9924), 1211-1221.

Kickz. (2009). Goals Thru football progress report: Monitoring and evaluation. London: Active Communities.

Kihl, L., Babiak, K., \& Tainsky, S. (2014). Evaluating the implementation of a professional sport team's corporate community involvement initiative. Journal of Sport Management, 28, 324-337.

Kohen, D. E., Leventhal, T., Dahinten, V. S., \& McIntosh, C. (2008). Neighborhood disadvantage: Pathways of effects for young children. Child Development, 79, 156-169.

Larkin, M., Richardson, E. L., \& Tabreman, J. (2012). New partnerships in health and social care for an 
era of public spending cuts. Health and Social Care in the Community, 20(2), 199-207.

Leventhal, T., \& Brooks-Gunn, J. (2000). The neighborhoods they live in: The effects of neighborhood residence on child and adolescent outcomes. Psychological Bulletin, 126, 309-337.

Levermore, R. (2011). Analysing the extent to which evaluation of corporate social responsibility for development through sport is conducted. Third World Quarterly, 32(3), 322-335.

Mellor, G. (2008). The janus-faced sport: English football, community and the legacy of the "Third Way". Soccer and Society, 9(3), 313-324.

Newbury-Birch, D., Gilvarry, E., McArdle, P., Stewart, S., Walker, J., Avery, L., Beyer, F., Brown, N., Jackson, K., Lock, C., McGovern, R., \& Kaner, E. (2009). The impact of alcohol consumption on young people: $A$ review of reviews. London: Department of Children Schools and Families.

Nixon, J., Hunter, C., Reeves, K., \& Jones, A. (2003). Tackling anti-social behaviour in mixed tenure areas. London: OPDM.

Ottesen, L., Jeppesen, R. S., \& Krustrtup, B. R. (2010). The development of social capital through football and running: studying an intervention program for inactive women. Scandinavian Journal of Medicine \& Science in Sports, 20(1), 118-131.

Parnell, D., \& Burrows, L. (2014). Burton Albion Community Trusts, Albion 2 Engage: Project report. Leeds: Leeds Metropolitan University.

Parnell, D., Hargreaves, J., Zwolinsky, S., McKenna, J., \& Pringle, A. (2014). Burton Albion Community Trusts, golden goal over 50's activity club: Project Report. Leeds: Leeds Metropolitan University.

Parnell, D., Millward, P. \& Spracklen, K. (2014). Sport and austerity in the UK: An insight into Liverpool 2014. Journal of Policy Research in Tourism, Leisure and Events. DOI: 10.1080/19407963.2014.968309

Parnell, D., Pringle, A., McKenna, J., \& Zwolinsky, S. (2014). Comments on Bruun, D.M. et al. Community-based recreational football: A novel approach to promote physical activity and quality of life in prostate cancer survivors. Int. J. Environ. Res. Public Health 2014, 11, 5557-5585-Time to raise our game. International Journal of Environmental Research and Public Health, 11(7), 6842-6843.

Parnell, D., \& Richardson, D. (2014). Introduction: Football and inclusivity. Soccer \& Society, 15(6), 823-827.

Parnell, D., Stratton, G., Drust, B., \& Richardson, D. (2013). Football in the Community Schemes: Exploring the effectiveness of an intervention in promoting healthful behaviour change. Soccer \& Society, 14(1), 35-51.

PAT 10. (1999). National strategy for neighbourhood renewal: Policy Action Team Audit. Report for the Policy Action Team 10. The contribution of sport and the arts. London: Department of Culture Media and Sport.

Pawson, R. (2006). Evidenced-based policy: A realist perspective. London: Sage.

Prezza, M., \& Pacilli, M. G. (2007). Current fear of crime, sense of community and loneliness in Italian adolescents: The role of autonomous mobility and play during childhood. Journal of Community Psychology, 35, 151-170.

Pringle, A., McKenna, J., \& Zwolinsky, Z. (2013). Health improvement and professional football: players on the same side? Journal of Policy Research in Tourism, Leisure and Events, 5(2) 207-212.

Pringle, A., Zwolinsky, S., McKenna, J., Roberston, S., Daly-Smith, A., \& White, \& A. (2014). Health improvement for men and hard-to-engage-men delivered in English Premier League football clubs. Health Education Research, 29, 503-520.

Pringle, A., Parnell, D., Rutherford, Z., McKenna, J., Zwolinsky, S., \& Hargreaves, J. (in press). Sustaining health improvement activities delivered in English professional football clubs using evaluation: A short communication. Soccer \& Society.

Ramella, M. (2004). Positive futures impact report: Engaging with young people. London: Home Office.

Ransdell, L., Dinger, M., Huberty, J., \& Miller, K. (2009). Planning physical activity programmes. Developing effective physical activity programmes. Champaign, Illinois: Human Kinetics.

Romeo-Velilla, M., Beynon, C., Murphy, R. C., McGee, C. E., Hilland, T. A., Parnell, D., Stratton, G., \& Foweather, L. (2014). Formative evaluation of a UK community-based sports intervention to prevent smoking among children and young people: SmokeFree Sports. Journal of Sport for Development, 2(3), 1-10

Rutherford, Z, Seymour-Smith, S., Matthews, C., Wilcox, J., Gough, B., Parnell, D., \& Pringle, A. (2014). Motivate: The effect of a football in the community delivered weight loss programme on over 35 year old men and women's cardiovascular risk factors. Soccer and Society, 15(6), 951-969.

Smith, A., \& Waddington, I. (2004). Using "sport in the community schemes" to tackle crime and drug use among young people: Some policy issues and problems. European Physical Education Review, 10, 279298.

Smith, A., \& Westerbeek, H. (2007). Sport as a vehicle for deploying corporate social responsibility. Journal of Corporate Citizenship, 25, 43-54.

South, J., \& Tilford, S. (2000). Perceptions of research and evaluation in health promotion practice and influences on activity. Health Education Research, 15(6), 729-741.

Tacon, R. (2007). Football and social inclusion: Evaluating social policy. Managing Leisure, 12(1), 1-23.

Tett, L. (2005) Partnerships, community groups and social inclusion. Studies in Continuing Education, 27(1), 1-15. 
UK Government (2003). Anti-social Behaviour Act 2003. Retrieved from http://www.legislation.gov.uk/ ukpga/2003/38/pdfs/ukpga_20030038_en.pdf

Walker, M., Heere, B., \& Kim, C. (2013). The paradox of social responsibility: Putting the "responsibility" back in CSR through program evaluation. In J. L. Paramio, K. Babiak, \& G. Walters (Eds.), The Handbook of Sport and Corporate Social Responsibility (pp. 309-316). New York: Routledge.

Walters, G. (2009). Corporate social responsibility through sport: The Community Trust model as a
CSR delivery agency. Journal of Corporate Citizenship, 35, 81-94.

Walters, G., \& Chadwick, S. (2009). Corporate citizenship in football: Delivering strategic benefits through stakeholder engagement. Management Decision, 47(1), 51-66.

Watson, N. (2000). Football in the Community: "What's the Score". Soccer and Society, 1(1), 114-125.

Youth Justice Board for England and Wales. (2011). Annual report and accounts. London: The stationary office.

\section{About the Authors}

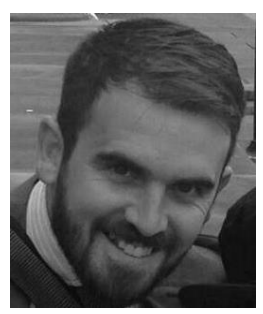

\section{Dr. Daniel Parnell}

Dr. Daniel Parnell is a Senior Lecturer in Sport Business Management and an active researcher. Dan is primarily interested in the social role of sport (specifically football). He currently conducts research with a number of football clubs in England and key strategic stakeholders in football, including the Football League Trust, the English Premier League and the Football Foundation (the UKs largest sports charity). Dan has been led a number of club based interventions based on his work within the Everton Active Family Centre and more recently the national evaluation of the Extra Time programme.

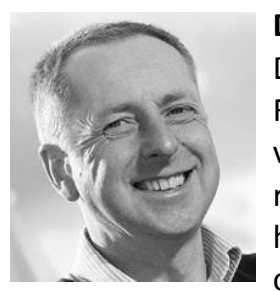

\section{Dr. Andy Pringle}

Dr. Andy Pringle is Reader in Physical Activity, Exercise and Health at Leeds Beckett University and Fellow of the Royal Society of Public Health. He has served as a topic expert on the Public Health Advisory Committee for the National Institute for Health and Care Excellence (physical activity/exercise referral). Andy also conducts/supervises research into the effectiveness of physical activity and public health interventions, including those delivered in football settings. He was involved in the evaluation of the Premier League Men's Health programme.

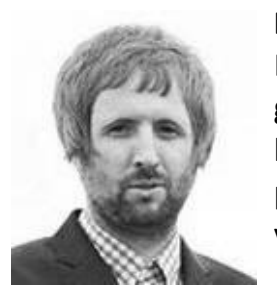

\section{Dr. Paul Widdop}

Dr. Paul Widdop Research Fellow in cultural sociology. His main research interests are in the sociology of taste and consumption in the fields of Sport and Music. Specifically, he is interested in exploring how social networks impact upon behaviour in these fields. He is also interested in the importance of place and neighbourhood effects in Sport and Music, especially in the mediating role they play in developing and sustaining cultural lifestyles and cultural communities.

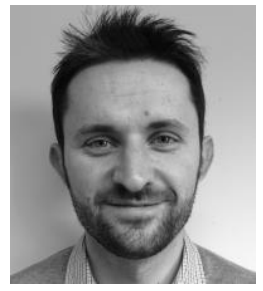

\section{Stephen Zwolinsky}

Stephen Zwolinsky is a researcher within the Centre for Active Lifestyles at Leeds Beckett University. His research has focused on establishing the impact of football led health interventions, and investigating the prevalence, combinations and clustering of lifestyle risk factors in hard-to-engage populations. He has also been involved in the national evaluation of Premier League Health and the Extra Time programme. 